\title{
Geopolítica da Rússia na região Anglo-Americana: política externa e aliança estratégica com o Brasil (2005 e 2017)
}

\section{Russia's Geopolitics in the Anglo-American region: foreign policy and strategic alliance with Brazil (2005 and 2017)}

Rev. Bras. Est. Def. v. 6, nº 1, jan./jun. 2019, p. 163-189 DOI: $10.26792 /$ RBED.v6n1.2019.75045

ARTHUR MASTROIANI MAXIMO DE LUCENA ALEXANDRE CESAR CUNHA LEITE FÁBIO RODRIGO FERREIRA NOBRE

\section{INTRODUÇÃO}

O presente artigo tem como objetivo principal analisar a reascensão da Rússia no cenário internacional pela sua política externa, usando como ponto de partida de análise sua aliança estratégica com o Brasil. Este objetivo fundamenta-se com a seguinte questão norteadora: diante da reascensão da Rússia no cenário internacional e do comprometimento desta de firmar alianças estratégicas através da sua política externa, em que medida a parceria entre Brasil e Rússia, firmada em 2005 e reconsolidada em 2017, auxilia neste processo de expansão russa, pela geopolítica?

Para isso, serão discutidos três pontos principais: a) contextualizar brevemente a relação Brasil e Rússia no governo de Fernando Henrique Cardoso e os primeiros anos do governo Lula, período anterior à declaração de aliança estratégica firmada em 2005; b) explicar o intuito da declaração de aliança estratégica entre Rússia e Brasil firmado em 2005 e con-

Arthur Mastroiani Maximo de Lucena - Mestre pelo Programa de Pós-Graduação em Relações Internacionais na Universidade Estadual da Paraíba (PPGRI-UEPB). Bacharel em Relações Internacionais pela Universidade Federal da Paraíba (UFPB). Membro do Grupo de Estudos e Pesquisa em Ásia-Pacífico (GEPAP - UEPB).

Alexandre Cesar Cunha Leite - Programa de Pós-Graduação em Relações Internacionais — Universidade Estadual da Paraíba e Programa de Gestão Pública e Cooperação Internacional — Universidade Federal da Paraíba.

Fábio Rodrigo Ferreira Nobre - Doutor em Ciência Política (UFPE). Docente do Programa de PósGraduação em Relações Internacionais - Universidade Estadual da Paraíba. 
tinuado em 2017 e; c) analisar interesses geopolíticos da política externa russa na América Latina, tendo o Brasil como porta de entrada.

A metodologia usada no artigo teve como ponto focal o estudo exploratório, conforme definição de Richardson (1999), em que se tem o interesse de entender consequências ou crenças de um fenômeno. Os principais autores que fazem parte da estrutura argumentativa do trabalho são estudiosos que têm foco total ou parcial na política externa da Rússia, do Brasil e nos estudos de geopolítica, conforme pode ser revisado nas referências propostas ao fim do artigo.

Para que a discussão de aliança estratégica proposta seja desenvolvida, antes é necessário termos o entendimento do que seria este tipo de aliança. Inicialmente, é importante enfatizar que não existe um conceito universal sobre o que viria a ser aliança estratégica, mas sim definições específicas que alguns autores propuseram. Além disso, nas duas Declarações analisadas, os termos "aliança" e "parceria" estratégica são apresentados sem distinção, ou seja, são tratados como sinônimos. Desta forma, serão apresentados os conceitos existentes na academia e o norteador do estudo

Klotzle (2002) traz à tona bem essa discussão, destacando justamente esta ausência, na academia, de uma conceitualização universal, e enfatizando segmentos de pesquisa voltados aos estudos de aliança estratégica, citando autores que contribuíram para seu entendimento. São eles: Teece (1992), Hagedoorn e Narula (1996), Dussauge e Garrette (1995; 1997), Lorange e Roos (1996) e Garai (1999) (Klotzle 2002).

Como pode ser visto no Quadro 1, são apresentadas cinco definições de alianças estratégicas que podem ser utilizadas para desenvolvimento de estudo científico. No caso proposto de aliança estratégica firmada entre Brasil e Rússia em 2005, e posteriormente reafirmada em 2017, enquadra-se no que é definido pelos autores Hagedoorn e Narula (1996). Para eles, estas alianças são classificadas em dois tipos, os que envolvem participação acionária e os que estão associados a contratos firmados entre parceiros. Brasil e Rússia, no estudo proposto, enquadram-se no segundo tipo, contratos firmados entre parceiros, em que são sugeridos "acordos de desenvolvimento conjunto de produtos, pactos de pesquisa conjunta, acordos mútuos de licenciamento e contratos de Pesquisa e Desenvolvimento (P\&D)” (Klotzle 2002). 


\section{Quadro 1}

Definição de aliança estratégica segundo a visão de diversos autores

\begin{tabular}{|c|c|}
\hline Autor & Definição de aliança estratégica \\
\hline Teece (1992) & $\begin{array}{l}\text { Acordos nos quais dois ou mais parceiros dividem o compromisso de } \\
\text { alcançar um objetivo comum, unindo todas as capacidades e recursos, } \\
\text { coordenando suas atividades. Uma aliança estratégica implica algum } \\
\text { grau de coordenação estratégica e operacional das atividades e inclui, } \\
\text { entre outras, as seguintes operações: atividades conjuntas de Pesquisa e } \\
\text { Desenvolvimento (P\&D), transferência mútua de tecnologia, concessão } \\
\text { de direitos exclusivos de produção e venda e acordos de cooperação na } \\
\text { área de marketing. Alianças estratégicas podem ou não envolver parti- } \\
\text { cipação acionária. }\end{array}$ \\
\hline $\begin{array}{l}\text { Hagedoorn e } \\
\text { Narula (1996) }\end{array}$ & $\begin{array}{l}\text { Alianças estratégicas podem ser classificadas de duas maneiras. De um } \\
\text { lado, existem tipos que envolvem participação acionária, com joint- } \\
\text {-ventures e companhias conjuntas de pesquisa. De outro lado, há formas } \\
\text { sem participação acionária, isto é, baseadas somente em contratos entre } \\
\text { parceiros. Nesse grupo encontram-se, entre outros, acordos de desen- } \\
\text { volvimento conjunto de produtos, pactos de pesquisa conjunta, acordos } \\
\text { mútuos de licenciamento e contratos de Pesquisa e Desenvolvimento } \\
\text { (P\&D). }\end{array}$ \\
\hline $\begin{array}{l}\text { Dussauge e } \\
\text { Garrette } \\
(1995,1997)\end{array}$ & $\begin{array}{l}\text { Projetos de colaboração implantados por firmas rivais, operando na } \\
\text { mesma indústria. As formas mantêm, entretanto, a sua independência. } \\
\text { Essa definição exclui, assim, fusões e aquisições, as quais levam à perda } \\
\text { de autonomia de pelo menos um parceiro. Também são excluídas parce- } \\
\text { rias verticais formadas por fornecedores e compradores. }\end{array}$ \\
\hline $\begin{array}{l}\text { Lorange e } \\
\text { Roos (1996) }\end{array}$ & $\begin{array}{l}\text { Empreendimentos de risco ao longo de uma escala contínua entre, de } \\
\text { um lado, transações em um mercado livre (mercado) e, de outro, a in- } \\
\text { ternalização total (hierarquia). Temos, assim, as seguintes opções de } \\
\text { alianças estratégicas em termos do grau de integração vertical com a } \\
\text { empresa mãe: fusões e aquisições, participação acionária, joint-venture, } \\
\text { empreendimento cooperativo formal e empreendimento cooperativo } \\
\text { informal. }\end{array}$ \\
\hline Garai (1999) & $\begin{array}{l}\text { Alianças estratégicas incluem acordos de esforços conjuntos na área de } \\
\text { marketing, atividades conjuntas de Pesquisa e Desenvolvimento (P\&D), } \\
\text { colaboração no desenvolvimento de novos produtos, transferência de } \\
\text { tecnologia e atividades de terceirização. Fusões e aquisições não são } \\
\text { consideradas alianças estratégicas. }\end{array}$ \\
\hline
\end{tabular}

Fonte: Klotzle (2002). Elaboração Própria.

Tratando a aliança estratégica como contratos firmados entre parceiros, principalmente envolvendo dois Estados, tem-se um resultado de criação de contratos bilaterais para alguns fins específicos. No caso do artigo proposto, serão destacadas três áreas principais que são ditas nos dois acordos de aliança estratégica entre Brasil e Rússia: a) a cooperação econômica, 
b) cooperação em segurança e c) a cooperação energético-tecnológica. A Figura 1 a seguir representa os quatro tipos de aliança estratégica que podem ser formadas por meio das definições apresentadas por Klotzle (2002), tendo os "contratos bilaterais" como norteador da aliança estratégica entre Brasil e Rússia.

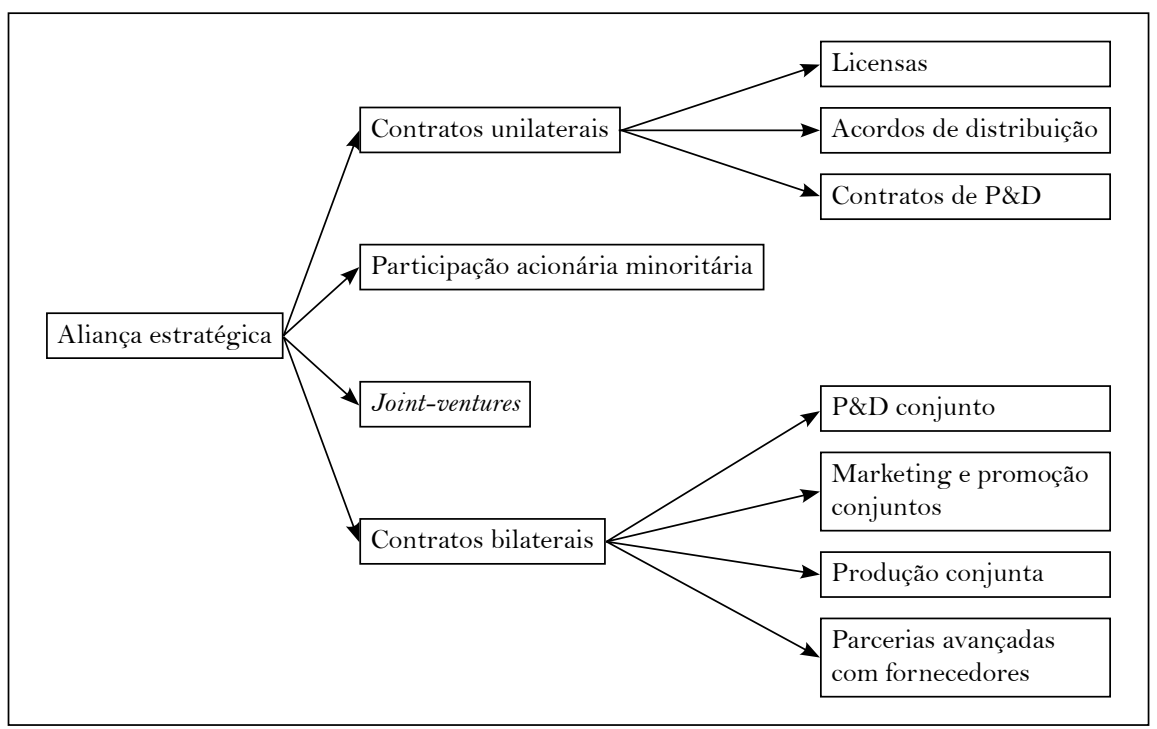

Figura 1 - Tipos de Alianças Estratégicas.

Fonte: Klotzle (2002).

Na Figura 2 foi realizada a aplicação da definição de contratos bilaterais envolvendo Brasil e Rússia em 2005 e 2017.

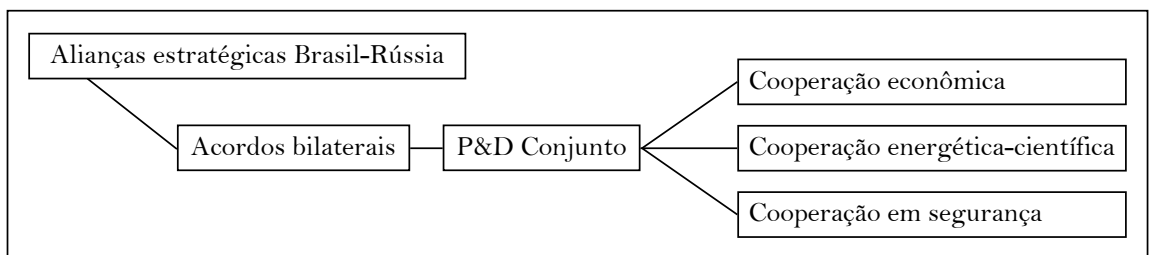

Figura 2 - Aplicação da definição Aliança Estratégica por contratos bilaterais entre Brasil e Rússia.

Fonte: Klotzle (2002). Elaboração própria. 
Tendo sido realizadas estas explicações iniciais, serão discutidos na próxima sessão os antecedentes da relação entre Brasil e Rússia, por meio dos quais se pode entender como as negociações iniciais influenciaram a formação da aliança estratégica em 2005.

\section{ANTECEDENTES: BRASIL E RÚSSIA NOS GOVERNOS FHC E LULA (1994-2004)}

Antes de entrar na discussão central, é importante destacar o movimento de expansão da Rússia, enfatizando o processo da política externa ${ }^{1}$ realizado no continente asiático e no Leste da Europa, visto que alianças estratégicas estão sendo feitas com frequência sob o governo de Vladimir Putin. Isto foi visto em algumas situações específicas, como a participação do país na Organização para Cooperação de Xangai (OCX), formalmente criada em $2001^{2}$ e que tinha o intuito da promoção da segurança dos países que integram a organização (China, Rússia, Uzbequistão, Cazaquistão, Quirguistão e Tadjiquistão), ${ }^{3}$ a posição da Rússia frente à Ucrânia, com contenção das investidas do mercado ocidental no país e a invasão à Crimeia (parte sul da Ucrânia), a reativação da base militar em Tartus (região marítima pertencente à Síria, mas que está novamente sob o domínio dos russos), dentre outros aspectos que mostram como a Federação da Rússia está ativamente expandindo-se pela sua política externa e influenciando medidas que vão de acordo com seus interesses políticos (Mielniczuk 2014; Naarajärvi 2012; Segrillo 2012).

No caso brasileiro, a Rússia tomou algumas iniciativas de contato com o país antes da Declaração de aliança estratégica de 2005 ser realizada. Porém, devido às dificuldades domésticas que a Rússia passava após o fim da URSS, com governo democrático e economia capitalista, não conseguiu avançar o contato com o Brasil na prática (Segrillo 2012). Para entendimento deste período, será tomado previamente como base o governo de Fernando Henrique Cardoso (1995-2003).

Nos anos de 1990, após o fim da URSS, a Rússia passava por um momento de transição muito conturbado economicamente e politicamente, em que se observou a intensificação do capitalismo no país e da inserção da democracia. Mesmo tendo iniciativas do Brasil e da Rússia para trocas de conhecimento, a exemplo da tecnologia nuclear por parte da Rússia e conhecimento bancário, gerenciamento global e agricultura capitalista pelo Brasil, a relação não seguiu adiante, visto que a Rússia passava justamente pelos processos domésticos mencionados. Internamente, a Rússia estava em crise econômica e política e não tinha como desenvolver quaisquer medidas de política externa com o Brasil (Hirst and Pinheiro 1995). 
É certo que já existia o interesse mútuo entre Brasil e Rússia no que tange a cooperação, e isto já era evidente em 1994, quando se firmou o "Tratado sobre as relações de parceria entre a República Federativa do Brasil e a Federação da Rússia”, um ano antes de Fernando Henrique Cardoso assumir o poder ${ }^{4}$ (Saraiva 2007).

Mesmo a Rússia estando em processo de reformulação doméstica da sua política e economia, durante o governo de Fernando Henrique Cardoso foi observado apoio ao Brasil na busca deste em conquistar o assento no Conselho de Segurança da ONU. Conforme Silva (2012) argumenta, países como Rússia, Portugal, Alemanha, China, Japão, Índia, África do Sul e Cabo Verde, todos eles fora do continente americano, apresentavam o apoio ao Brasil no Conselho de Segurança. O interessante deste alinhamento com o Brasil é que já se observava os países que futuramente comporiam os BRICS (Brasil, Rússia, Índia, China e África do Sul) apresentando apoio no cenário internacional (Silva 2012).

Boa parte da ideia de parceria estratégica que o Brasil adotou neste período deu-se pelo apoio mútuo que a maioria dos países citados anteriormente proporcionaram ao país. No caso dos Estados que futuramente formariam o BRICS, foi mais fácil a aproximação destes em específico, visto que economicamente eles tinham os mesmos interesses, seu mercado era considerado em expansão ou emergente e queriam posição semelhante no cenário internacional, ou seja, posição mais igualitária (Silva 2012).

Voltando à posição política e econômica da Rússia nos anos de 1990 e como se deu a relação com o Brasil no governo FHC, Bacigalupo (2000) traz uma contextualização interessante. Em síntese, argumenta que o país passou a integrar-se com o Ocidente e o mundo capitalista como um todo, administrando ao mesmo tempo seu esquema de segurança que já existia durante a URSS. Além disso, as diversas crises domésticas pelas quais a Rússia passava na década de 1990 não ajudavam a sua relação com o Brasil avançar. Mesmo assim, é interessante perceber, no que tange à diplomacia entre os dois países, a identificação de semelhanças, como, por exemplo, o crescimento econômico semelhante, os traços territoriais (comumente chamados de "países baleia”), grande volume populacional e com potencial avanço na globalização, fenômeno esse que crescia no Sistema Internacional na década em questão. Imerso nesta contextualização entre Brasil e Rússia, no governo de Fernando Henrique Cardoso, áreas como espacial e nuclear eram de interesses brasileiros para desenvolvimento de pesquisa, e alguns acordos foram firmados para desenvolvimento destes, porém sem muito avanço na prática (Bacigalupo 2000).

Em outras palavras, pelo processo rápido de reestruturação doméstica e de inserção no capitalismo pelo qual a Rússia passou após o fim da URSS, 
a Federação queria inserir-se novamente como ator relevante no Sistema Internacional. Para isto, focou mais precisamente em sua relação com países capitalistas desenvolvidos. Não apenas existia o interesse claro em melhorar sua economia, mas também estabilizar-se no Sistema Internacional ainda como um país relevante nas questões globais. Este fato veio à tona mais claramente no início do século XXI, na liderança de Vladimir Putin, que optou por um governo sob a ótica de "Estado forte e centralizador", tanto domesticamente como na sua política externa, ao mesmo tempo em que intensificou o mercado energético do país pela economia de mercado capitalista (Segrillo 2012).

Passando ao início do governo Lula da Silva, com relação à política externa do Brasil, Lula quis manter as boas práticas que já vinham sendo realizadas pelo Brasil e intensificar outros segmentos no cenário internacional. No caso da Rússia, houve novamente o intuito de firmar de forma concreta uma parceria estratégica ${ }^{5}$ com o país. Contextualizando com o período, o Brasil teve uma coordenação política e iniciativas comerciais mais incisivas, além da Rússia, com a Índia, África do Sul e China, mais uma vez já visando a parcerias futuras com os países mencionados, que culminaria, em 2006, na formação do BRIC (o BRICS, com a adição da África do Sul, foi oficializado apenas em 2011). Especificamente com Rússia e China foram ampliados intercâmbios comerciais, tecnológicos e militares, intensificando assim avanços significativos comparados com o governo anterior do Brasil (FHC) (Vigenani and Cepaluni 2007).

Outro aspecto interessante na relação Brasil e Rússia foi o apoio brasileiro com relação à entrada da Rússia na Organização Mundial do Comércio (OMC), em troca do compromisso destes de não reduzir o acesso de carnes brasileiras no mercado russo, durante cinco anos.

Durante o governo de Lula da Silva, foi perceptível a mudança do envolvimento entre Brasil e Rússia com relação à política externa dos dois países. Isto ocorreu devido ao que os dois países estavam vivendo naquele momento: a Rússia enfim começava a sair de uma crise doméstica que a acompanhou nos anos de 1990 sob o governo de Yeltsin, e o Brasil tinha uma expansão clara de sua política externa no Sistema Internacional como um todo, em que se observavam alianças com diversos países. A Rússia apresentava-se estrategicamente como um parceiro importante neste momento de expansão brasileira ${ }^{6}$ (Segrillo 2012; Vigevani and Cepaluni 2007).

Vizentini (2006) deixa claro que, durante o governo Lula, este intuito de parcerias estratégicas tinha como objetivo fortalecer o multilateralismo no Sistema Internacional, e o princípio de democratização das relações internacionais foi defendido de forma clara. $\mathrm{O}$ argumento defendido por Vizentini sugere que a intenção de manter e aprofundar o contato com 
potências emergentes, a exemplo da África do Sul, China e Rússia, bem como o fortalecimento da relação do Mercosul com a União Europeia e reconhecimento das OI's (Organizações Internacionais), além das vantagens econômicas que estas aproximações propiciavam, tinha a ideia de contribuição ao Sistema Internacional em uma dinâmica mais multipolar (Vizentini 2006).

Também é importante destacar que, neste momento da política externa brasileira, Lula devolveu ao Itamaraty uma melhor posição estratégica no que diz respeito à política externa do país, tendo em vista que no governo anterior, de FHC, este tinha dominado o âmbito político do organismo, ou seja, a autonomia do Itamaraty era inferior ao que se observou durante o governo Lula. Esta mudança foi primordial para que o Brasil tivesse uma atuação mais forte no âmbito externo e claramente isto deu resultados positivos na sua relação com a Rússia, já que, com o Itamaraty mais independente, há espaço para desenvolver o contato com outros organismos internacionais e descentraliza do executivo este papel (Vizentini 2006).

Com essa breve contextualização envolvendo Brasil e Rússia até os primeiros anos do governo de Lula da Silva, serão discutidas as análises das duas Declarações de parceria estratégica entre os dois países e a intenção geopolítica existente por parte do governo Putin.

\section{GEOPOLÍTICA RUSSA E AS DECLARAÇÕES DE ALIANÇA ESTRATÉGICA BRASIL-RÚSSIA (2005 E 2017): COOPERAÇÃO ECONÔMICA, DE SEGURANÇA E ENERGÉTICA-TECNOLÓGICA}

Passado a contextualização da relação Brasil e Rússia pelos governos de FHC e os primeiros anos do governo Lula, ${ }^{7}$ percebeu-se que os dois países convergiam para firmar um novo acordo de parceria estratégica, formalizado no que foi chamado de "Declaração Conjunta sobre os Resultados das Conversações oficiais entre o Presidente da República Federativa do Brasil, Luiz Inácio Lula da Silva, e o Presidente da Federação da Rússia, Vladimir V. Putin”, em 18 de outubro de 2005. Dentre os diversos temas presentes na declaração, serão destacadas três áreas principais: a cooperação econômica, de segurança e a energética-tecnológica. Estas três características serão importantes na contextualização de uma visão mais ampla do estudo, que seria a vertente geopolítica da Rússia ligada às três áreas destacadas. Muito do que a declaração de 2005 apresenta foi previamente formalizado no Tratado de 1994, mas, conforme foi exposto, nada saiu do papel de fato na época, devido às dificuldades que a Rússia enfrentava domesticamente durante os anos de 1990 (Silva 2012; Concordia 2005). 
Primeiramente, sob a ótica econômica, foram formalizados, na declaração de 2005, os pontos positivos que os dois países já tinham divulgado em diversos fóruns globais, como o apoio do Brasil à Rússia relativo à sua entrada na OMC e os avanços dos acordos comerciais bilaterais entre Brasil e Rússia, dando saltos significativos na balança comercial - apenas nos sete primeiros meses de 2005 foi registrado um superávit de 2,1 bilhões de dólares envolvendo produtos com alto valor agregado, muito influenciado pela cooperação econômica e da convergência de interesses (Concordia 2005). Estes avanços econômicos demonstraram maior proximidade nas questões internacionais envolvendo os governos de Brasil e Rússia, com a ampliação da cooperação no plano bilateral e nos fóruns multilaterais, característica esta densamente traçada no governo Lula e que a Rússia compartilhava.

Já no âmbito da segurança, a Rússia reafirmou seu apoio ao Brasil para que este fizesse parte do Conselho de Segurança da ONU, fato já evidenciado ainda sob o governo de FHC. Questões mais atuais, como terrorismo e tráfico de drogas, bem como contrabandos de pessoas ou quaisquer práticas contrárias aos direitos humanos defendidos pela Organização das Nações Unidas (ONU) também fazem parte da agenda de segurança dos dois países, tratando de forma objetiva e clara contra quaisquer financiamentos que estas práticas venham a acarretar dentro de seus territórios. Houve ainda a reafirmação do Tratado de Não Proliferação Nuclear (TNP), apoio ao desarmamento e acesso à tecnologia militar apenas para fins pacíficos. Neste quesito, também houve a reafirmação da proibição de testes nucleares com fins de destruição. Estes alinhamentos de agenda em segurança serviram de apoio para reforçar a cooperação entre eles (Concordia 2005).

Com relação à cooperação energética-tecnológica, a declaração foi bem mais enfática. Destacou-se a maior participação russa na construção de usinas hidrelétricas no Brasil, fortalecimento da coordenação entre empresas do setor do petróleo e do gás, da área petroquímica dos dois países, intercâmbio de experiências na área de energias renováveis, em particular o etanol. Todos estes elementos específicos fizeram com que os dois Estados firmassem uma parceria privilegiada na área de energia-tecnologia. Houve também o compromisso que esta parceria privilegiada seria colocada em prática à luz do uso racional dos recursos energéticos e a promoção do desenvolvimento sustentável, com tecnologias ecologicamente limpas (Concordia 2005). Numair (2009) acrescenta ainda no mesmo âmbito:

a) fornecimento de equipamentos russos para hidrelétricas de Porto Góes e Corumbá 3; b) proposta de participação de empresas e especialistas russos na produção no Brasil de turbinas de gás para usinas de energia elétrica; c) Gazprom e Petrobrás discutem coopera- 
ção mútua para exploração de jazidas de gás no Brasil e construção de gasoduto Venezuela-Chile-Brasil-Argentina (Numair 2009, 144).

Em comparativo com a declaração de 2017, firmada em 21 de julho, chamada de "Declaração Conjunta da República Federativa do Brasil e da Federação da Rússia sobre Diálogo Estratégico em Política Externa” basicamente reafirmou as mesmas características já apresentadas em 2005, mas com algumas mudanças específicas com relação à cooperação econômica e de energia-tecnologia. Sob a perspectiva econômica, a vertente multilateral ficou mais bem definida no documento mais recente, com a manutenção e fortalecimento do G-20, do sistema multilateral de comércio, tendo como foco as normas e princípios da OMC. Os consensos internacionais pelo grupo do G-20 foram reafirmados pela Rússia e Brasil nos termos que são de interesses convergentes ao grupo. Ainda sobre a OMC, formalizou-se o discurso de defesa de uma OMC multilateral, aberta, transparente, não discriminatória e inclusiva, ou seja, totalmente contrária ao protecionismo dos países desenvolvidos, visto que a taxa de crescimento global caiu e tanto o Brasil quanto a Rússia declararam participação em contribuir com o retorno do aumento (Concordia 2017).

Para a cooperação energética, inseriram o discurso de defesa dos ideais da AIEA (Agência Internacional de Energia Atômica) para fins pacíficos da tecnologia militar. Foi firmada a ampliação da cooperação na área do uso da energia nuclear para fins pacíficos nas seguintes esferas: "tecnologias de radiação e medicina nuclear, ciclo de combustível nuclear, preparação e capacitação de especialistas na área de uso da energia nuclear com fins pacíficos, conclusão das obras de Angra 3 e construção de novas usinas nucleares no território do Brasil” (Concordia 2017). Sob a ótica de desenvolvimento da energia global, foi formalizado debates nos fóruns internacionais no que tange a exploração do petróleo e do gás natural, energia nuclear, energias renováveis (incluindo bioenergias), aumento da eficiência energética, estudos científicos e desenvolvimento tecnológico (Concordia, 2017).

Por fim, a Rússia inseriu um novo discurso na Declaração de 2017 que entra em concordância com o que tem feito no Leste Europeu e Ásia, que seria sua expansão da política externa mais ativamente para outros continentes, no caso o americano. Segue o que foi exposto nos pontos 31 ao 34 da declaração de 2017 :

31. A Rússia destaca seu desejo de desenvolver relações multifacetadas com os países da América Latina e do Caribe, região que é importante centro de influência política e econômica do mundo contemporâneo multipolar. 
32. O Brasil ressalta sua disposição de contribuir para a promoção dos contatos da Federação da Rússia com as estruturas de integração da América Latina e do Caribe.

33. A Rússia e o Brasil saúdam a realização da reunião ministerial entre o Quarteto da Comunidade de Estados Latino-Americanos e Caribenhos (CELAC) e a Rússia, em 14 de novembro de 2016, em Sochi, que definiu as principais diretrizes da cooperação entre a CELAC e a Rússia no quadro do Mecanismo Permanente do Diálogo Político e Cooperação criado em 2015.

34. A Rússia e o Brasil tencionam trabalhar em conjunto para a celebração, com maior brevidade possível, do Memorando de Cooperação em Questões Econômicas e Comerciais entre a Comissão Econômica Euroasiática e os Governos dos países membros do Mercado Comum do Sul - Mercosul (Concordia 2017).

Na prática, observa-se que a Rússia já iniciou um processo de expansão da sua política externa para fora do continente euroasiático, muito focado nos processos de integração regional e organismos internacionais. Esta perspectiva da Rússia de expansão de sua política externa no continente americano está em concordância com o que tem feito no continente asiático, pela teoria do neoeurasianismo. ${ }^{8}$ Esta corrente teórica, que nasceu do eurasianismo ${ }^{9}$ e defendida por Aleksander Dugin (2014), entende que a Rússia deve honrar suas características individuais, mesmo geograficamente pertencente a uma parte europeia e outra asiática. Rejeita preceitos liberais e práticas ocidentais de desenvolvimento, busca expandir sua política, economia e geopolítica através de filosofia própria russa. Caracterizado pela cultura eslavófila, ${ }^{10}$ estes valorizam a importância da tradição, de sua história e apoiam a separação da Rússia de aspectos do padrão ocidental. Copiar formas de "democracia liberal" é sinônimo de insensatez (Dugin 2014). O autor também associa o eurasianismo com práticas geopolíticas e enfatiza que esta corrente teórica busca entender todo o globo a partir do ponto de vista geográfico e histórico, excluindo o lado Ocidental da civilização do mundo, além de tentar compreender o Sistema Internacional a partir do ponto de vista militar estratégico. Sob o aspecto cultural e social, argumenta que "Em termos de cultura, ele deseja a preservação e o desenvolvimento das tradições nacionais, étnicas e religiosas orgânicos; e, do ponto de vista social, que abrange todas as diversas formas de vida econômica e esforços para a 'sociedade socialmente justa”' (Dugin 2014, 17).

Mesmo que o neoeurasianismo tenha suas raízes no continente asiático, tem em seu entendimento muito da ideologia russa e que, consequente- 
mente, vem se apresentado nas medidas de política externa do país, principalmente em relações bilaterais, parcerias estratégicas e convergência de interesses (Dugin 2014). Neste caso, o Brasil encaixa-se perfeitamente neste tipo de expansão da política externa russa.

Complementando o argumento, o neoeurasianismo não é identificado apenas como uma teoria geopolítica, mas também uma filosofia que possui características históricas, geográficas, estratégicos, militares, culturais e sociais. Entende a dominação do Ocidente nas questões globais, mas rejeita esse tipo de pensamento. Une os Estados que não aceitam as políticas expansionistas da OTAN e dos Estados Unidos, preserva as características culturais e tradições nacionais próprias, bem como étnicas e religiosas e representa uma forma diferenciada de vida econômica (Manuel 2018).

Em aspectos geopolíticos, Rússia e Brasil possuem muitas semelhanças em seu território, o que contribui para fortalecer ainda mais este direcionamento que a política externa russa vem assumindo e a que o Brasil vem se alinhando, além de outras características econômicas e populacionais que convergem entre os dois países. Conforme Saraiva (2007) discute, Brasil e Rússia são Estados que não estão integrados estruturalmente a regiões mais amplas, nem tampouco ocupam polos centrais, ou seja, possuem imenso território e mesmo assim tem "autonomia na formulação de suas ações internacionais e [...] aumentam sua capacidade de negociação na esfera internacional" (Saraiva 2007: 54).

Além disso, enxergam a globalização como uma saída para desenvolvimento mútuo até o nível de potência e preferem não ficar marginalizados na periferia. Desta forma, "são os candidatos naturais a ter lugar de destaque na nova ordem mundial” (Saraiva 2007, 54).

Outra característica que Brasil e Rússia têm em comum, de acordo com o que a US Trade Representative ${ }^{11}$ expõe, seria o de nações com grande mercado emergente em âmbito doméstico e com potencial regional. $\mathrm{O}$ fator econômico geralmente une interesses entre os Estados e esta semelhança entre os dois países seria um elemento positivo. Esta identificação como "emergente" veio do entendimento de Estados que são vistos como periféricos e que implementaram o receituário do Consenso de Washington (liberalização comercial, privatização, reforma do Estado e desregulamentação da economia), melhorando seu mercado interno como consequência (Lima 2005).

Em suma, Brasil e Rússia possuem semelhanças como sua dimensão continental, reconhecidas potências regionais nos processos de integração regional que estão inseridos, nível populacional parecido, Produto Interno Bruto (PIB) semelhante, recursos naturais disponíveis a seu favor, mercado emergente em ascensão e tudo isso dentro de um regime democrático for- 
malmente aplicado a nível estatal. Estas características moldaram o interesse entre os dois países de realizar parcerias estratégicas, já comentadas anteriormente (Saraiva 2007).

A seguir, segue quadro comparativo entre os dois países, com foco em âmbitos econômicos, políticos e em desenvolvimento. As variáveis selecionadas dizem respeito ao interesse comparativo Rússia-Brasil para reforçar o argumento de semelhança entre os Estados e a convergência de interesses para reforçar a aliança estratégica.

\section{Quadro 2}

Comparativo econômico entre Brasil e Federação Russa 12

\begin{tabular}{|l|c|c|}
\hline \multicolumn{1}{|c|}{ Variáveis } & Federação Russa & Brasil \\
\hline Entrada de turistas & 32.421 .000 turistas & 6.430 .000 turistas \\
\hline Gastos públicos com educação & $4,1 \%$ do PIB & $5,8 \%$ do PIB \\
\hline Gastos públicos com saúde & $6,5 \%$ do PIB & $9,7 \%$ do PIB \\
\hline $\begin{array}{l}\text { Investimentos em pesquisa e } \\
\text { desenvolvimento }\end{array}$ & $1,13 \%$ do PIB & $1,15 \%$ do PIB \\
\hline $\begin{array}{l}\text { Mulheres de 15 anos ou mais de } \\
\text { idade economicamente ativas }\end{array}$ & $56,76 \%$ & $60,03 \%$ \\
\hline PIB per capita & US $\$ 9.243$ & $69,7 \%$ \\
\hline $\begin{array}{l}\text { População de 15 anos ou mais } \\
\text { de idade economicamente ativa }\end{array}$ & $63,4 \%$ & 828 \\
\hline Total da exportação & US $\$ 497.833,53$ milhões & US $\$ 225.098,41$ milhões \\
\hline Total da importação & US $\$ 286.648,78$ milhões & US $\$ 229.060,06$ milhões \\
\hline Total do PIB & US $\$ 1.326 .016$ milhões & US\$ 1.772.591 milhões \\
\hline
\end{tabular}

Fonte: IBGE (2018). Elaboração Própria.

Como se percebe no quadro 2 , a exemplo dos "investimentos em pesquisa e desenvolvimento", "mulheres de 15 anos ou mais de idade economicamente ativas", "PIB per capita", "População de 15 anos ou mais de idade economicamente ativa", "total de importação" e "total do PIB” são resultados bastantes semelhantes, confirmando assim o que foi defendido anteriormente entre os dois países, argumentado por Saraiva (2007).

Voltando a atenção para a visão geopolítica que a Rússia vem tomando nas suas relações exteriores via política externa, conforme Dugin (2014) contextualiza pela teoria do neoeurasianismo, o mundo contemporâneo está tomado de forças ocidentais que manipulam o processo de globalização e o mercado capitalista de forma unipolar. Com isto, a teoria reforça que se 
faz necessário uma força contrária para intervir neste tipo de manipulação dos países centrais, ou, como o autor chama, de "atlantismo" ocidental, para que haja de fato um multilateralismo entre todos os países, sem protecionismo de mercado e contrário à "globalização unilateral” (Dugin 2014).

Um exemplo prático deste processo pode ser observado sobre as novas medidas militares russas na região do Ártico. Para contrabalancear as forças militares dos EUA na região, e com isso conter a influência Ocidental, no governo de Dmitri Medvedev (2008-2012), e mais ativamente no de Putin (2000-2008 e 2012-presente), investiu-se gradativamente em armamento bélico na marinha e em submarinos para fortalecer a segurança da Rússia e conter ameaças que poderiam surgir desta área. A globalização, com busca de novos recursos naturais para investimento comercial, e o descongelamento consequente das calotas polares fizeram com que se tivesse melhor acesso a área e, com isso, empreendeu-se uma investida militar russa no Ártico de forma mais ativa. As medidas realizadas fizeram com que se ressaltasse uma dualidade de políticas militares e de defesa da Federação Russa, que seria a manutenção do equilíbrio entre a busca da supremacia do país na região, mas, ao mesmo tempo, com o cuidado de não chegar a uma provocação com o Ocidente, mantendo assim a diplomacia com os países ocidentais já conquistada desde o fim da Guerra Fria (Vecchioli 2018).

Como pode ser observado na expansão da política externa da Rússia no século XXI, ainda sobre o exemplo anterior, a Rússia tem demonstrado o interesse e a capacidade de projetar a sua influência e interesses na região do Ártico. Por um lado, compreende a importância da cooperação internacional reforçada na região nas suas estratégias. Porém, por outro, apresenta um posicionamento direcionado para a segurança e a militarização da região, ocasionando uma dualidade de suas intenções reais no Ártico. Este fator de dúvida é um aspecto importante que marca a política externa da Rússia, definida em sua agenda, fazendo com que sua atuação venha revestida de imprevisibilidades, resultando em desconfianças por parte do Ocidente (Silva 2018).

Voltando ao argumento inicial do neoeurasianismo, para que esta força capitalista que impulsiona uma globalização unipolar do mercado seja impedida, Dugin (2014) apresenta uma nova proposta, chamada de "globalização multipolar". Nesta proposta, o mundo seria dividido em quatro macrorregiões ou zonas (Zona Anglo-Americana; Zona Euro-Africana; Zona Pan-Eurasiana e Zona do Extremo Oriental Pacífico) e cada uma possuindo várias áreas de convergência, chamadas de "grandes espaços". $\mathrm{Na}$ prática, seria a nova realidade do mundo multipolar, com economia mais aberta e zonas de influências de mercados mais igualitários. No caso 
da Rússia, ela teria um papel importante como ator no sistema internacional em fortalecer a "globalização multipolar" e teria parcerias estratégicas no globo por meio de sua política externa (Dugin 2014).

Neste sentido, na prática o neoeurasianismo não aceita o antigo modelo de centro-periferia. Defende que o mundo seria constituído por uma gama de espaços vivos com relativa autonomia e com abertura para conexão do tipo multipolar. Estes espaços vivos não seriam Estados-Nação em si, mas sim uma coligação de Estados identificados como federações continentais. Para Dugin (2014), cada uma destas áreas teria características econômicas multipolares, com diferenciação de fatores administrativos, culturais, religiosos e étnicos (Dugin 2014; Manuel 2018).

Conforme pode ser visto nos dois mapas a seguir, percebe-se a divisão do mundo nas quatro macrorregiões (Zona Anglo-Americana; Zona EuroAfricana; Zona Pan-Eurasiana e Zona Pacífico Extremo Oriental), bem como os grandes espaços que as compõem e as zonas de influência, tendo a Rússia papel importante neste novo processo chamado de "globalização multipolar".

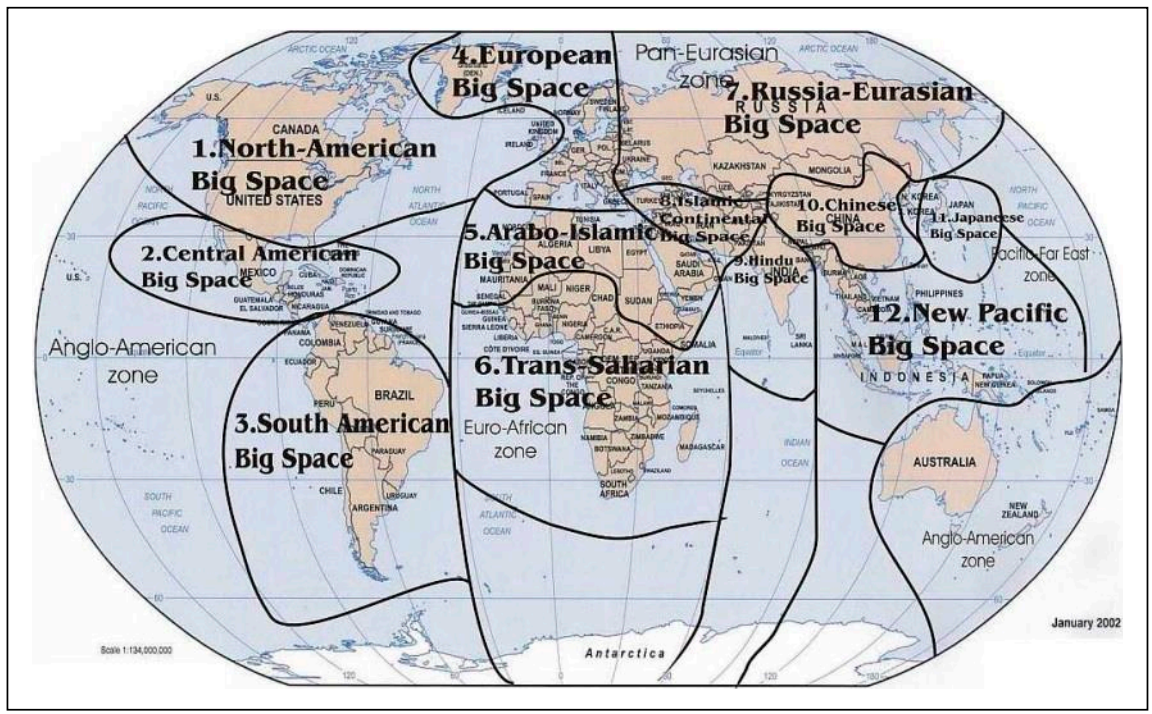

Mapa 1 - Mundo multipolar. Quatro zonas - grandes espaços.

Legenda: 1. Grande espaço da América do Norte; 2. Grande espaço da América Central; 3. Grande Espaço da América do Sul; 4. Grande espaço Europeu; 5. Grande espaço ÁrabeIslâmico; 6. Grande espaço Trans-Saariano; 7. Grande espaço Russo-Eurasiático; 8. Grande espaço Continente Islâmico; 9. Grande espaço Hindu; 10. Grande espaço Chinês; 11. Grande espaço Japonês; 12. Grande espaço Novo Pacífico. Tradução livre.

Fonte: Dugin (2014). 
A seguir segue mapa com relação ao movimento de contra estratégia eurasiana:

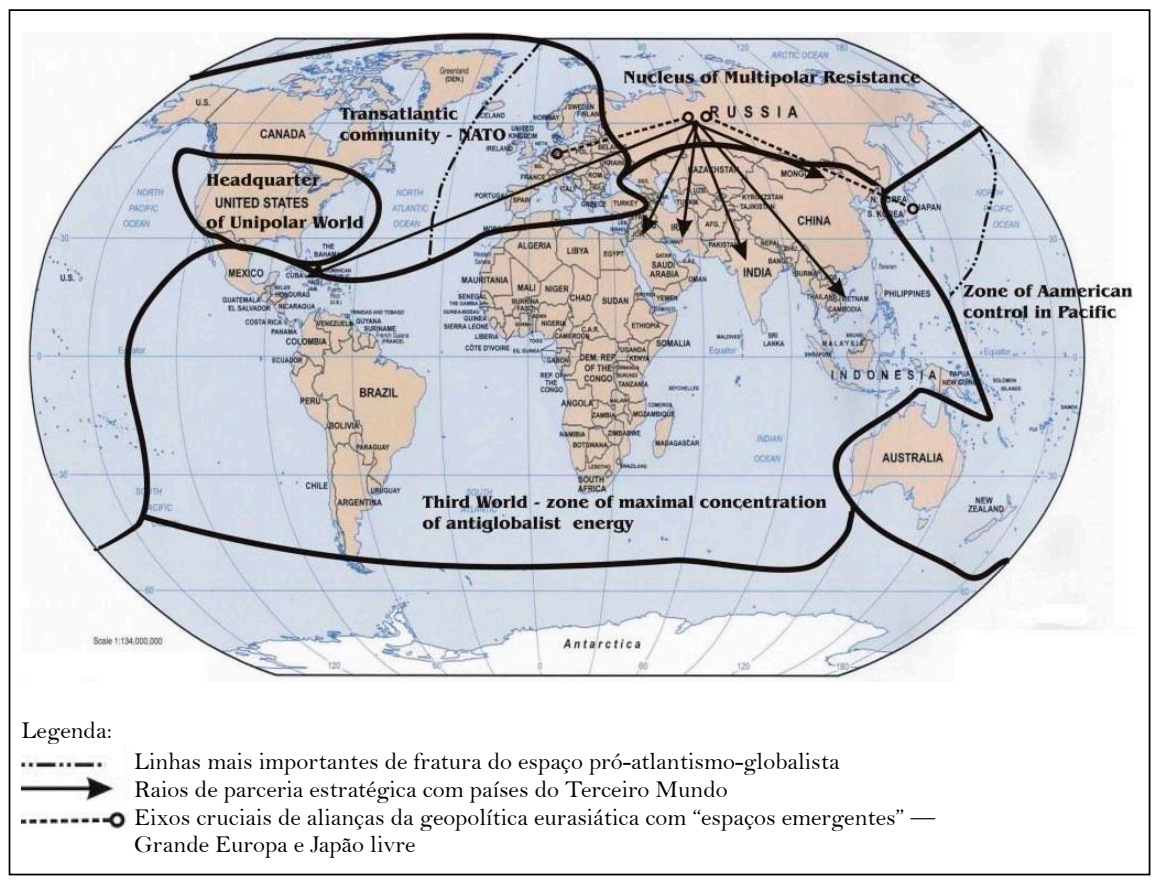

Mapa 2 - Reação Russo-Eurasiana contra a globalização unipolar. Contra estratégia. Fonte: Tradução livre a partir de Dugin (2014).

No Mapa 1 (Mundo multipolar. Quatro zonas - grandes espaços), percebe-se claramente as quatro zonas principais e seus grandes espaços no mundo multipolar defendido pela teoria neoeurasiana. No caso do Brasil, o país ficaria na zona Anglo-americana e pertencente ao grande espaço da América do Sul. Fazendo um comparativo com que se observa nas declarações de 2005 e 2017 entre Rússia e Brasil, o Brasil é um país estratégico de fato aos russos na América do Sul, e esta parceria pode estender-se ainda mais para outro grande espaço da zona Anglo-Americana, que seria a América Central, com foco no Caribe. Como a Rússia ainda não tem de fato um aliado forte em sua política externa na América Central por causa da influência dos Estados Unidos, o Brasil poderia representar esta âncora no continente americano para expansão da política externa russa e contenção da globalização unipolar capitalista dos países desenvolvidos nas Américas. 
Este argumento também ganha força quando se visualiza o Mapa 2 (Reação Russo-Eurasiana contra a globalização unipolar. Contra estratégia), na medida em que se pode notar as regiões de interesse da Rússia no mundo, associado aos países do Terceiro Mundo. Nas Américas, o foco principal é o Caribe, que geograficamente é um ponto de partida interessante tanto ao norte quanto ao sul do continente para expansão da política externa da Rússia e consequente contenção da globalização unipolar dos países desenvolvidos. Voltando a atenção ao Brasil, na Declaração de 2017 a Rússia deixa claro que o Brasil é um parceiro importante na sua política externa com os processos de integração regional sul-americano e principalmente como ponte em sua relação com o Caribe. Conforme já mencionado nos trechos 31 e 32 da Declaração de 2017, a intenção é clara na realização da ponte estratégica Rússia - Brasil - Caribe.

Diante do exposto, pode-se deduzir que as investidas de cooperação entre Rússia e Brasil, iniciados formalmente em 2005 (mesmo possuindo um histórico de contato diplomático nos anos de 1990) até o ano de 2017 , foca-se muito na cooperação em setores de interesse convergente entre os dois países, seja na segurança, economia ou no setor energético-tecnológico, que foi o enfoque da análise das duas Declarações aqui expostas. Mais que isso, em uma visão de cunho geopolítico, percebe-se que o interesse russo vai mais além: intrinsecamente ligado a questões da dinâmica da globalização e do mercado capitalista, há um interesse em mudar a realidade econômica. Conforme Dugin (2014) vai expor em sua teoria neoeurasiana, deve-se conter o tipo de globalização unipolar, que é dominado pelos países desenvolvidos do centro (Estados Unidos e União Europeia principalmente) e torná-la uma globalização multipolar, dinamizando os grandes espaços divididos em quatro zonas em todo o globo e diminuindo os protecionismos da onda "atlantista" - sinônimo para os países desenvolvidos que dominam a globalização unipolar (Dugin 2014).

Neste processo, o Brasil considera sua relação com a Rússia uma forma de fortalecer a cooperação bilateral com a Federação e consequentemente o multilateralismo com os países do Terceiro Mundo, já que Brasil e Rússia têm destaque regional nos processos de integração em que estão envolvidos, a exemplo do Mercosul (Mercado Comum do Sul) e APEC (Cooperação Econômica da Ásia e do Pacífico), bem como o intuito de fortalecer o discurso de abertura dos mercados e contenção dos protecionismos dos países desenvolvidos. Esta parceria estratégica com a Rússia também dá acesso a tecnologias que podem proporcionar desenvolvimento ao país, principalmente nos âmbitos da economia, segurança e do setor energético-tecnológico. Antes mesmo de firmar a Declaração de 2005 entre Brasil e Rússia, já enfatizava-se a contribuição russa em ceder cientistas de qualida- 
de para desenvolvimento técnico-científico em áreas específicas no Brasil, e, em contrapartida, pelo Brasil ser mais dinâmico em alguns setores de sua economia, poderia aplicar o conhecimento científico russo, gerando absorção de novas tecnologias nesta parceria bilateral (Bacigalupo 2000).

Mais que uma expansão da sua política externa, a Rússia tem o intuito de mudar o fluxo da globalização mundial, de unipolar para multipolar, e muito desses interesses convergem com seu parceiro estratégico brasileiro. Existe a necessidade no Terceiro Mundo dos mercados serem mais acessíveis e com menos barreiras. Mesmo que a Rússia tenha um interesse geopolítico forte por trás deste processo, pela visão da teoria neoeurasiana, a necessidade de crescimento multipolar na economia de mercado para os países periféricos e terceiro-mundistas faz com que exista uma convergência de interesses entre eles (Silva 2012). Conforme Silva (2012) expõe, a política multilateral que as potências médias realizavam "significava o abandono do discurso terceiro-mundista e da compreensão internacional baseada no conflito Norte-Sul, com a adesão do mainstream internacional e a substituição, conforme os discursos governamentais, do modelo de "autonomia pela distância” pelo de “autonomia pela participação” (Fonseca Jr. 1998, apud Silva 2012).

Enquanto a globalização multilateral não se fortalece, a saída para os países não desenvolvidos continua sendo o que Richard Haass chama de "multilateralismo regionalista”, em que explica a proliferação de arranjos bilaterais ou regionais para crescimento, já que no plano global a tentativa de se inserir continua baixa (Haass 2010).

Desta forma, inserindo a contextualização política e econômica dos dois países com os acordos de parceria estratégica firmados, a tendência é de que se fortaleça esse alinhamento dos dois Estados ao longo do tempo, já que existem de ambas as partes interesses mútuos de aproximação, a exemplo das três áreas destacadas no presente estudo, visto que, como argumenta Haas (2010), no âmbito global, a inserção é mais complexa e fechada.

\section{CONSIDERAÇÕES FINAIS}

Mesmo que nos anos de 1990 já existisse um interesse em cooperação, a relação bilateral do Brasil e Rússia, de maneira mais palpável, pôde ser observada já no governo de Lula da Silva, no início do século XXI, com a Declaração de parceria estratégica firmada em 2005 e que foi reafirmada em 2017.

Inseridos em um contex to cooperativo, as declarações trouxeram à tona o desejo mútuo entre os dois países de colaboração em áreas específicas 
que gerassem crescimento, a exemplo do que foi exposto no presente artigo (economia, segurança e o setor energético-tecnológico). Além disso, percebeu-se também a intenção de fortalecer o multilateralismo, com o intuito de estimular suas economias e inserir-se mais ativamente no mercado capitalista.

Esta parceria estratégica também demonstrou uma tendência que está acontecendo na política externa da Rússia, que seria a contenção da "globalização unipolar” e a implementação de outro fluxo de mercado, chamado de "globalização multipolar". Idealizado pela teoria neoeurasianista, tem o intuito de conter a manipulação dos países desenvolvidos do mercado mundial e, em contrapartida, traz a proposta de abertura dos mercados, com maior dinamização da economia, quebra das barreiras protecionistas e fortalecimento das relações multilaterais entre os países do Terceiro Mundo, em desenvolvimento e desenvolvidos.

Em termos geopolíticos, para a Rússia, o Brasil seria estratégico não apenas para crescimento em setores específicos, mas também seria porta de entrada para outros Estados do continente americano, continuando assim a formação de outras parcerias estratégicas, principalmente com o Caribe. Conforme foi defendido na Declaração de parceria estratégica, em 2017, ficou claro que a Rússia pretende utilizar sua aproximação com o Brasil para fazer uma "ponte" com o Caribe, expandindo assim consequentemente sua política externa e colocando em prática o ideal de uma globalização mais multilateral. Conforme observado no Mapa 2 (Reação Russo-Eurasiana contra a globalização unipolar. Contra estratégia) pôde-se observar os pontos estratégicos no globo onde a Rússia tem interesse em manter uma relação mais predominante e, no caso da zona Anglo-Americana, a região focal seria o Caribe. Como o Brasil possui diversos pontos em comum com a Rússia para crescimento bilateral, tendo o fortalecimento do multilateralismo como grande interseção entre os dois países, é possível que o país se apresente como âncora nesta expansão da política externa russa e do ideal da globalização multilateral no continente americano.

\section{REFERÊNCIAS}

Azevedo, Beatriz M., Fred Leite S. Campos, and Sergio Roberto G. Lopes. 2017. Neo-Eurasianismo, geopolítica e a política externados EUA à URSS durante a guerra fria. Rev. Bra. Est. Def. 4, no. 1 (Jan./Jun.): 229-251. https://rbed.abedef. $\mathrm{org} / \mathrm{rbed} /$ article/view/72786/42047.

Bacigalupo, Graciela Zubelzú de. 2000. As relações russo-brasileiras no pós-Guerra Fria. Rev. bras. polit. int. 43, no. 2 (Dec.): 59-86. http://www.scielo.br/scielo. 
php? script $=$ sci_arttext\&pid $=$ So034 $-73292000000200003 \& \operatorname{lng}=$ en\&nrm $=$ iso $>$. access on 18 Feb. 2018. http://dx.doi.org/10.1590/So034-73292000000200003.

Bailes, Alyson J. K., Pál Dunay, Pan Guang, and Mikhail Troitskiy. 2007. Sipri Policy Paper - The shanghai cooperation Organization. SIPRI Policy Paper 17 (Maio). https://www.sipri.org/sites/default/files/files/PP/SIPRIPP17.pdf.

Centro de História e Documentação Diplomática (CHDD). 1994. Tratado sobre as relações de parceria entre a República Federativa do Brasil e a Federação da Rússia, 1994. http://funag.gov.br/chdd/images/Resenhas/RPEB_75_jul_dec_1994.pdf.

Concordia. 2005. Declaração Conjunta sobre os Resultados das Conversações Oficiais entre o Presidente da República Federativa do Brasil, Luiz Inácio Lula da Silva, e o Presidente da Federação da Rússia, Vladímir V. Pútin. Atos internacionais. Itamaraty. Governo Federal do Brasil. https://concordia.itamaraty.gov.br/detalhamento/ 5476 .

Concordia. 2017. Declaração Conjunta da República Federativa do Brasil e da Federação da Rússia Sobre Diálogo Estratégico em Política Externa. Atos internacionais. Itamaraty. Governo Federal do Brasil. https://concordia.itamaraty.gov.br/ detalhamento/11994

Dugin, Aleksander. 2014. Eurasian Misson An Introduction to Neo-Eurasianism. Arktos.

Dugin, Aleksander. 2012. The FourthPolitical Theory. http://www.4pt.su/pt-br/ node/33.

Dussauge, P., and B. Garrette. 1995. Determinants of success in international strategic alliances: evidence from the global aerospace industry. Journal of International Business Studies 26, 505-530. https://link.springer.com/article/ $10.1057 \% 2$ Fpalgrave.jibs. 8490848

1997. Anticipating the evolutions and outcomes of strategic alliances between rival firms (the construction, forms, and consequences of industry networks). International Studies of Management and Organization 27, no. 4: 104-116. https://www.tandfonline.com/doi/abs/10.1080/00208825.1997.11656720?journalCode $=$ mimo 20 .

Ferreira, Marcos Farias, and João Terrenas. 2016. Good-bye, Lenin! Hello, Putin! O discurso geoidentitário na política externa da nova Rússia. Rev. Bras. Ciênc. Polit. no. 20 (Aug.): 43-78, http://www.scielo.br/scielo.php? script=sci_arttext\&pid=S0103-33522016000200043\&lng=en\&nrm=iso. http://dx.doi. org/10.1590/0103-335220162002. 
Garai, G. 1999. Leveraging the rewards of strategic alliances. Journal of Business Strategy (Mar.-Apr.). https://www.emeraldinsight.com/doi/abs/10.1108/ ebo39994.

Geopolitica.ru Portal. 2016. Map of Russian-Eurasian reaction against unipolar globalization. Counterstrategy. https://www.geopolitica.ru/sites/default/files/map-4-big.jpg

Haass, R. N. 2010. The case for messy multilateralism. Financial Times (January). https://www.ft.com/content/18d8f8b6-fa2f-11 de-beed-00144feab49a.

Hagedoorn, J., and R. Narula. 1996. Choosing organizational modes of strategic technology partnering: international and sectoral differences. Journal of International Business Studies (Second Quarter): 265-284. https://link.springer. $\mathrm{com} /$ article/ $10.1007 \% 2 \mathrm{FBF} 00214825$.

Hirst, Monica, and Letícia Pinheiro. 1995. A política externa do Brasil em dois tempos. Rev. Bras. Polít. Int. 38, no. 1: 5-23. Instituto Brasileiro de Geografia e Estatística. Economia Brasil. https://paises.ibge.gov.br/\#/pt/pais/brasil/info/ economia.

Instituto Brasileiro de Geografia e Estatística. Economia Federação Russa. 2018. https://paises.ibge.gov.br/\#/dados/russia-federacao-russa.

Klotzle, Marcelo Cabus. 2002. Alianças estratégicas: conceito e teoria. Rev. Adm. Contemp. 6, no. 1 (Apr.): 85-104. http://www.scielo.br/scielo.php? script=sci_arttext\&pid=S1415-65552002000100006\&lng=en\&nrm=iso. http://dx.doi. org/10.1590/S1415-65552002000100006.

Lima, Maria Regina Soares de. 2005. A política externa brasileira e os desafios da cooperação Sul-Sul. Revista Brasileira de Política Internacional 48, no. 1 (JaneiroJunho): 24-59. Instituto Brasileiro de Relações Internacionais. Brasília. http:// www.redalyc.org/articulo.oa?id=35848102.

Lorange, P., and J. Roos. 1996. Alianças estratégicas: formação, implementação e evolução. São Paulo: Atlas.

Manuel, Héric Sequeira Ramos. 2018. "A reformulação da política externa russa durante a presidência Putin-Medvedev". 260f. Dissertação (Mestrado) Universidade de Lisboa, Instituto Superior de Ciências Sociais e Políticas (ISCSP). https://www.repository.utl.pt/handle/10400.5/14725.

Mielniczuk, Fabiano. 2014. A crise ucraniana e suas implicações para as Relações Internacionais. Revista Conjuntura Austral 5, no. 23 (Abr./maio). https://www.aca- 
demia.edu/14925140/A_Crise_Ucraniana_e_suas_Implica\%C3\%A7\%C3\%B5es_ para_as_Rela\%C3\%A7\%C3\%B5es_Internacionais.

Naarajarvi, Teemu. 2012. China, Russia and the Shangai Cooperation Organisation: Blessing or Curse for New Regionalism in Central Asia? Asia Europe Journal 10. https://link.springer.com/article/10.1007\%2Fs 10308-012-0329-z.

Numair, Eliane. 2009. Brasil e Rússia: do confronto ideológico à parceria estratégica. Revista Relações Internacionais no Mundo Atual 1, no. 9. http://revista.unicuritiba.edu.br/index.php/RIMA/article/view/277

Office of the United States Trade Representative. About us. https://ustr.gov/ about-us.

Ribeiro, Erik Herejk. (2017). "A Expansão da Organização para a Cooperação de Xangai (OCX): Uma Coalizão Anti-Hegemônica?” I Seminário Internacional de Ciência Política, Estado e Democracia em Mudança no século XXI. I Seminário Internacional de Ciência Política (Set.), Porto Alegre. Universidade Federal do Rio Grande do Sul. https://www.ufrgs.br/sicp/wp-content/uploads/2015/09/ RIBEIRO-A-Expans\%C3\%A 3o-da-Organiza\%C $3 \%$ A 7\%C 3\%A 3o-paraa-Coopera\%C3\%A 7\%C3\%A3o-de-Xangai-Uma-Coaliz\%C3\%A3o-Antihegem\%C3\%B4nica.pdf.

Richardson, R. J. 1999. Pesquisa social: métodos e técnicas. São Paulo: Atlas, 1999.

Saraiva, Miriam Gomes. 2007. As estratégias de cooperação Sul-Sul nos marcos da política externa brasileira de 1993 a 2007. Rev. bras. polít. int. 50, no. 2 (Dec.): 42-59. http://www.scielo.br/scielo.php? script=sci_arttext\&pi$\mathrm{d}=$ So034-73292007000200004\&lng=en\&nrm=iso >. http://dx.doi.org/10.1590/ S0034-73292007000200004.

Segrillo, Angelo. 2012. A questão da democracia na Rússia pós-soviética. In: Alves, André Gustavo de Miranda Pineli (Org.). O renascimento de uma potência? A Rússia no século XXI. Brasília: IPEA. Cap. 3: 97-128. http://repositorio.ipea.gov. $\mathrm{br} / \mathrm{handle} / 11058 / 3042$.

Silva, André Luis Reis da. 2012. O Brasil diante da globalização: a política externa do governo Fernando Henrique Cardoso (1995-2002). Carta Internacional 7, no. 1: 20-34. https://cartainternacional.abri.org.br/Carta/article/view/8/29

Silva, Carolina Sofia Nóbrega da. 2018. "A Geopolítica do Ártico e a política externa da Rússia para aregião (2007-2017)”. 84f. Dissertação (Mestrado). Universidade de Lisboa, Instituto Superior de Ciências Sociais e Políticas (ISCSP). https://www.repository.utl.pt/handle/10400.5/14847. 
Teece, D. J. 1992. Competition, cooperation, and innovation: organizational arrangements for regimes of rapid technological progress. Journal of Economic Behavior and Organization 18: 1-25. https://www.sciencedirect.com/science/article/pii/016726819290050L.

Vecchioli, Valter. 2018. "As relações EUA - Rússia relativamente à questão Ártica”. 101f. Dissertação (Mestrado). Universidade Nova de Lisboa, Faculdade de Ciências Sociais e Humanas (FCSH), Departamento de História. https://run. unl.pt/handle/10362/31564.

Vigevani, Tullo, and Gabriel Cepaluni. 2007. A política externa de Lula da Silva: a estratégia da autonomia pela diversificação. Contexto Int. 29, no. 2 (Dec.): 273-335. http://www.scielo.br/scielo.php?script=sci_arttext\&pi$\mathrm{d}=$ So 102-85292007000200002\&lng=en\&nrm=iso $>$. http://dx.doi.org/10.1590/ S0102-85292007000200002.

Vizentini, Paulo Fagundes. 2006. De FHC a Lula: uma década de política externa (1995-2005). Civitas - Revista de Ciências Sociais [S.1.] 5, no. 2 (Dez.): 381-397. ISSN 1984-7289. http://revistaseletronicas.pucrs.br/ojs/index.php/civitas/article/view/9/1602. 


\section{NOTAS}

1. Existem outros mecanismos de análise para entendimento de expansão russa ao longo do século XXI, como as transformações domésticas na econômica, política e melhora social da população com o aumento do PIB, comparado aos anos de 1990 sob a gestão de Yeltsin (Segrillo 2012). Todavia, a presente pesquisa opta pelo foco nesta expansão no que tange à política externa no país.

2. Apenas em 2002, foram assinados dois documentos importantes entre os Estados-membros: a Declaração dos Chefes de Estado e a "Carta de Princípios” da Organização para Cooperação de Xangai. Importantes documentos que definiram as funções, os deveres e os direitos da Organização, em que se identificou na prática a Organização como sujeito de Direito Internacional (Bailes, Dunay, Guang, and Troitskiy 2007).

3. Índia e Paquistão entram na Organização para Cooperação de Xangai em 2015 (Ribeiro 2015).

4. Seguem alguns apontamentos do Tratado (1994): [...] as Partes colaborarão em organizações internacionais de natureza econômica, comercial e financeira, tendo em vista o desenvolvimento econômico de ambas. [...] contribuirão para o desenvolvimento da cooperação econômica, comercial e tecnológica, mediante também a identificação de novas formas de interação em setores de interesse mútuo, tais como agroindústria, indústria de bens de consumo, metalurgia, construção de máquinas, energia, desenvolvimento de transportes e outros ramos da infraestrutura. [...] Fomentarão e estimularão a cooperação científica e tecnológica em áreas como utilização da energia nuclear com fins pacíficos, pesquisa e aproveitamento pacífico do espaço exterior, eletrônica, informática, biotecnologia, genética, desenvolvimento de novos materiais e em outros domínios de interesse mútuo, bem como tomarão medidas para a realização de programas de pesquisa conjunta na esfera de tecnologias de ponta (Centro de História e Documentação Diplomática, 1994-2 $2^{\circ}$ semestre) (CHDD 1994).

5. Conforme apresentado no início do artigo, nos documentos analisados, "parceria" e "aliança" estratégica são dados como sinônimos. Todavia, será levado em consideração o conceito discutido pelos autores Hagedoorn e Narula (1996), no que tange a contratos firmados entre parceiros.

6. Ênfases precisas: (1a) aprofundamento da Comunidade Sul-americana de Nações (Casa); (2a) intensificação das relações entre países emergentes como Índia, China, Rússia e África do Sul; (3a) ação de destaque na Rodada Doha e na Organização Mundial do Comércio, assim como 
em algumas outras negociações econômicas; (4a) manutenção de relações de amizade e desenvolvimento das relações econômicas com os países ricos, inclusive com os Estados Unidos; (5a) retomada e estreitamento das relações com os países africanos; (6a) campanha pela reforma do Conselho de Segurança das Nações Unidas, visando um lugar de membro permanente para o Brasil; e (7a) defesa de objetivos sociais que permitiriam maior equilíbrio entre Estados e populações (Vigevani and Cepaluni 2007, 292).

7. É preciso destacar que, entre os governos de FHC e Lula da Silva, no Brasil, foi o período em que a Rússia passou por uma recuperação doméstica, tanto econômica, com o controle da inflação, como de reestruturação política, quando Putin assume o poder, no início do século XXI. Com isso, o Estado russo pôde, de fato, olhar para sua política externa de forma mais independente, colocando em prática vários acordos bilaterais, inclusive envolvendo parceria estratégica, e o Brasil estava no seu raio de interesse.

8. "Neoeurasianismo é a escola geopolítica russa que defende que a atual Federação Russa, assim como a antiga URSS e o Império Russo, é representante do Heartland mackinderiano e, por isso, a mais forte potência terrestre existente, sendo o seu território e entorno imediato o palco da luta global com a mais forte potência marítima atual, os EUA. Então, se de um lado a potência marítima representava os ideais ocidentais da liberdade individual, dos direitos humanos, da democracia liberal, etc., a potência terrestre teria representado sempre os valores do coletivismo, da tradição, da hierarquia, etc.” (Azevedo, Campos, and Lopes 2017, 244-245).

9. “O Eurasianismo clássico, nascido nos anos 1920, considerava a Rússia um continente intermédio, uma massa homogênea, distinta tanto da Ásia como da Europa, e que, apesar de combinar elementos de ambos, constituía-se essencialmente como melting point cultural da população eslava e turcomana. Seria então este sincretismo a base da específica etnicidade russa” (Ferreira and Terrenas 2016, 47).

10. Eslavófilos são os que consideravam a Rússia uma civilização única e que deveria seguir um caminho próprio, independente do Ocidente. Também é considerada parte da sociedade mais madura com ascendência russa e que apoia os velhos costumes e regimes antes adotados na região (Segrillo 2012).

11. "The Office of the United States Trade Representative (USTR) is an agency of more than 200 committed professionals with decades of specialized experience in trade issues and regions of the world. We negotiate directly with foreign governments to create trade agreements, to resolve 
disputes, and to participate in global trade policy organizations. We also meet with governments, with business groups, with legislators and with public interest groups to gather input on trade issues and to discuss the President>s trade policy positions. USTR was created in 1962 and has offices in Washington, Geneva, and Brussels" (US Trade Representative 2017,1).

12. O IBGE coletou as informações de diversas fontes para os dois Estados. Para maior detalhamento sobre as variáveis (Entrada de turistas; Gastos públicos com educação; Gastos públicos com saúde; Investimentos em pesquisa e desenvolvimento; Mulheres de 15 anos ou mais de idade economicamente ativas; PIB per capita; População de 15 anos ou mais de idade economicamente ativa), acessar o site do IBGE. 


\section{RESUMO}

O artigo tem como objetivo apresentar a relação entre Brasil e Rússia, analisando duas Declarações de parceria estratégica formalizadas em 2005 e 2017, imersos na temática econômica, em segurança e no setor energético-tecnológico. Conseguinte, serão abordadas questões geopolíticas russas pela teoria neoeurasiana e o papel do Brasil como parceiro estratégico.

Palavras-chave: Brasil; Rússia; Neoeurasianismo; Parceria Estratégica.

\section{ABSTRACT}

This paper aims to discuss the relation between Brazil and Russia making an analysis of two Strategic Partnership Declaration made in 2005 and 2017, it will be focused on three areas: economy, security and the energy-technology sector. Consequently, Russian geopolitical issues will be addressed by the neoeurasian theory and the role of Brazil as a strategic partner.

Keywords: Brazil; Russia; Neoeurasianism; Strategic Partnership. 